\title{
SEVERE BILATERAL CORNEAL DERMOID CYST WITH NASAL HYPERPLASTIC TISSUE IN A CALF
}

\author{
M. A. Hashim ${ }^{1}$, N. M. Shafy ${ }^{2}$, M. K. S. A. Millat ${ }^{2}$, P. K. Bhattacharjee' ${ }^{2}$ B. S. Ahmed ${ }^{2}$, R. R. Sarker ${ }^{2}$ and \\ M. S. Rahman ${ }^{2 *}$
}

${ }^{1}$ Department of Surgery and Obstetrics, ${ }^{2}$ Department of Medicine, Faculty of Veterinary Science, Bangladesh Agricultural University, Mymensingh-2202, Bangladesh.

\begin{abstract}
Dermoid cyst is an uncommon developmental anomaly usually congenital or hereditary in nature which can result from either defective genetics or from a genetic insult/agent that's associated with the fetal environment or from their interaction. Dermoid cysts and congenital diseases are not most common in Bangladesh and the economic effect of congenital defects is not as high as compare with that of other diseases that have high economic effects. The main objective of this study is to report severe bilateral corneal dermoid with nasal hyperplastic tissue in a calf and its therapeutic measurements attended in veterinary teaching hospital, BAU.
\end{abstract}

Key words: Congenital, bilateral, dermoid cyst, hyperplastic tissue, calf

\section{INTRODUCTION}

Congenital means present at birth and is not synonymous with hereditary (Samad, 2008). Ocular dermoid is a skin or skin-like appendage usually arising on the limbus, conjunctivae, and cornea that may be unilateral or bilateral and associated with other ocular manifestation or with other malformations. Hair from the lesions is predominantly responsible for the associated irritation resulting in chronic inflammation of the conjunctivae and cornea and may cause visual impairment (Barkyoumb and Leipold, 1984; Greene et al., 1973; Moore et al., 1999). Dermoids may affect the eyelids, conjunctiva, nictitans, sclera and cornea (Lawson, 1975) and most commonly present unilaterally. Bilateral ocular dermoids have been reported in cattle (Barkyoumb and Leipold, 1984; Yeruham et al., 2002) and in camel (Moore et al., 1999). Ocular dermoids are rare in cattle, with the prevalence estimated between $0.002 \%$ and $0.4 \%$ (Yeruham et al., 2002). A study on bovine congenital defects was carried out in Bangladesh and ocular system was recorded including dermoid cyst (7.14\%) (Hasan et al., 2015; Samad, 2002). This paper reports a case of bilateral large dermoid cyst and nasal hyperplastic tissue in a calf.

\section{CASE HISTORY}

A two days old calf had been admitted at veterinary teaching hospital, Faculty of veterinary science, Bangladesh Agricultural University, Mymensingh with a complain of difficulty vision with extra growth of conjunctiva with an abnormal appearance of both eyes and difficulty in breathing with a sign of open mouth breathing since birth. A large fleshy mass was attached to the cornea and sclera with a large number of temporally and superiorly directed hairs arising from the surface of the mass resulting blindness and continuous lacrimation. An overgrowth in nostril resulting difficulty in breathing and open mouth breathing. The clinical diagnosis was bilateral corneal dermoids and nasal hyperplastic tissue.

The calf was admitted to the veterinary teaching hospital after initial examination. The calf weighed 25kg, was in good bodily condition and no other abnormalities were detected on physical examination.

*Corresponding e-mail address: prithul02@yahoo.co.uk 


\section{A. Hashim and others}

\section{TREATMENT}

After clinical examination, calf was prepared for surgical excision of dermoid cysts. As the calf was 2 days old the operation was performed in two successive attempts of 7 days apart instead of both eyes at a time. The operation site was prepared for aseptic surgery by shaving, scrubbing and application of mild antiseptic solution. The calf was sedated with Diazepam 10mg (Sedil ${ }^{\circledR}$, Square Pharmaceuticals,Dhaka, Bangladesh) $2 \mathrm{~mL}$ ampoule, IM and restrained on table in lateral recumbency. Auriculopalpebral and Peterson nerve was blocked by local infiltration with $2 \%$ lignocaine hydrochloride (Jasocaine ${ }^{\circledR}$, Jayson Pharmaceuticals, Dhaka, Bangladesh) $5 \mathrm{~mL}$. The cysts were excised by superficial lamellar keratectomy that was extended into the third eyelid, medial canthus, eyelid and bulbar conjunctiva. Cysts were carefully dissected from all adherent areas, stalks were ligated with chromic catgut (No. 1). The nasal masses were excised with first eye operation.

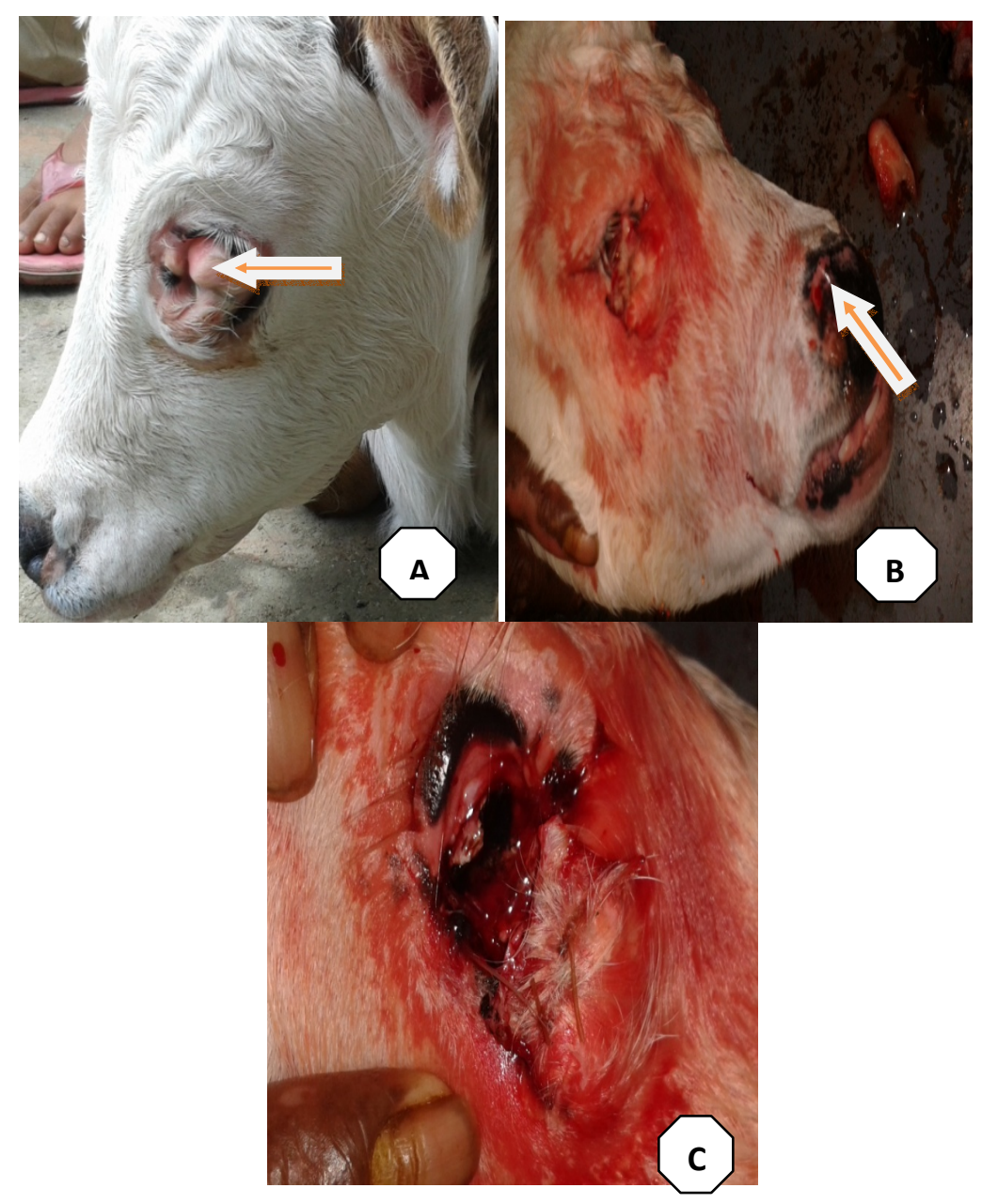

Figure1. Surgical correction of dermoid cyst: (A). Severe Dermoid cyst in calf, (B). Nasal Hyperplastic tissue, (C). After surgery 


\section{POSTOPERATIVE TREATMENT AND FOLLOW UP}

Systemic amoxicillin 100mg/mL (Moxacil vet $\left.{ }^{\circledR}\right) 2 \mathrm{~mL} 48$ hours interval were administered IM for five days in addition to a local antibiotic and anti-inflammatory (for eye instillation). The calf recovered uneventfully. The calf was again examined after one month for rule out any reoccurrence. Re-examination after one month did not reveal any re-occurrence of dermoid cysts.

\section{REFERENCES}

1. Barkyoumb SD and Leipold HW (1984). Nature and cause of bilateral ocular dermoids in Hereford cattle. Veterinary Pathology 21: 316-324.

2. Greene HJ, Leipold HW and Huston K (1973). Congenital defects in cattle. Irish Veterinary Journal 27: 37-45.

3. Hasan MS, Rahaman MM, Sen AB, Islam MS, Khan MSI and Matin MA (2015). Prevalence of congenital defects of cattle and goat in Bangladesh. International Journal of Natural and Social Sciences 2: 13-17

4. Lawson DD (1975). Corneal dermoids in animals. Veterinary Record 97: 449-450.

5. Moore CP, Shaner JB, Halenda RM, Rosenfeld CS and Suedmeyer WK (1999). Congenital ocular anomalies and ventricular septal defect in a dromedary camel (Camelus dromedarius). Journal of Zoo and Wildlife Medicine 30: 423-430.

6. Samad MA (2002). Bangladesh Veterinary Journal. 36: 07-14

7. Samad MA (2008). Bovine congenital defects in Bangladesh. Animal Husbandry and Veterinary Science. V-2, 1127. First Published. LEP Publication No. 11. BAU Campus, Mymensingh, Bangladesh.

8. Yeruham I, Perl S and Liberboim M (2002). Ocular dermoid in dairy cattle - 12 years survey. Revue de Médecine Véterinaire 153: 91-92. 